\title{
1984: O FUTURO DISTÓPICO ENTRE NÓS
}

\section{4: EL FUTURO DISTÓPICO ENTRE NOSOTROS}

Sigrid Rochele Gusmão Paranhos Magalhães Universidade do Estado da Bahia - UNEB, DCH, VI/Caetité

Larissa Lopes Meira

Universidade do Estado da Bahia - UNEB, DCH, VI/Caetité

Valdineide Jesus de Oliveira

Universidade do Estado da Bahia - UNEB, DCH, VI/Caetité

\section{Resumo}

O presente artigo objetiva apresentar algumas reflexões provenientes da análise do livro, 1984, de George Orwell, no intuito de poder comparar o romance com a atual sociedade brasileira, bem como compreender os diversos sujeitos na contemporaneidade e suas relações via mídias e redes sociais nesse contexto de globalização. Para tanto, este estudo está ancorado em teorias filosóficas, literárias e sociais, sob a perspectiva de teóricos como Arendt (2012), Bauman (2001), Foucault (2009), Sousa Santos (2005), entre outros. A metodologia adotada pauta-se numa abordagem qualitativa, de cunho bibliográfico, num processo comparativo, interpretativo e reflexivo. Constatase que o livro apresenta traços atemporais ao contexto sócio-histórico em que foi produzido e ajusta-se como um alerta para as sociedades capitalistas. O enredo permeia por variados aspectos, que interligam fatos políticos, econômicos e tecnológicos, trazendo em sua abordagem um possível futuro em que a maioria dos sujeitos deverão abdicar de sua liberdade, em detrimento de um regime totalitário. Por fim, conclui-se que Orwell, em 1984, teve uma grande contribuição ao prever, através de seu romance, uma sociedade pautada pelo poder de uma minoria hegemônica que explora as mais diversas camadas 
sociais, de forma hierarquizada e politicamente situada, não muito diferente da sombria realidade desse país chamado Brasil.

Palavras-Chave: Controle. Distopia. Manipulação. Totalitarismo.

\section{Resumen}

El presente artículo objetiva presentar algunas reflexiones provenientes del análisis del libro, 1984, de George Orwell, com el intuito de poder comparar la novela con la sociedad brasileña actual, así como comprender los diversos sujetos en la contemporaneidad y sus relaciones a través de los medios y las redes sociales en ese contexto de globalización. Con este fin, este estudio está anclado en teorías filosóficas, literarias y sociales, desde la perspectiva de teóricos como Arendt (2012), Bauman (2001), Foucault (2009), Sousa Santos (2005), entre otros. La metodología adoptada se basa en un enfoque cualitativo, de naturaleza bibliográfica, en un proceso comparativo, interpretativo y reflexivo. Se constata que el libro presenta rasgos atemporales al contexto sociohistórico en el que fue producido y se ajusta como una alerta para las sociedades capitalistas. La trama impregna varios aspectos, que interconectan hechos políticos, económicos y tecnológicos, trayendo a su enfoque un posible futuro en el que la mayoría de los sujetos deberá abdicar de su libertad, en detrimento de un régimen totalitario. Finalmente, se concluye que Orwell, en 1984, tuvo una gran contribución al predecir, através de su novela, una sociedad guiada por el poder de una minoría hegemónica que explora las capas sociales más diversas, de una manera jerárquica y políticamente situada, no muy diferente de la sombría realidad de ese país llamado Brasil.

Palabras clave: Control. Distopía. Manipulación. Totalitarismo.

\section{Introdução}

Este estudo surge a partir de leituras e reflexões do livro 1984, do escritor inglês Eric Arthur Blair (1903 - 1950), considerado um dos mais influentes escritores do século XX, sob o pseudônimo de George Orwell. Apesar de ser uma obra publicada há 70 anos atrás, em 
1949, nos chama a atenção a estreita relação com a atual conjuntura sócio-política do Brasil. Daí, o nosso interesse em investigar o contexto histórico em que o livro foi escrito, descrever os elementos característicos do gênero literário distópico ${ }^{i}$ procurando entender os seus possíveis desdobramentos e averiguar a intersecção entre os dois contextos: o ficcional, a partir da obra 1984, e o real, com base no cenário brasileiro. Em seguida, esta pesquisa ainda propõe analisar até que ponto os meios de comunicação conseguem controlar a sociedade na contemporaneidade. Para tanto, iremos fundamentar esse trabalho, tomando como base os estudos de Arendt (2012), Foucault (2009), Jacoby (2007), Sousa Santos (2005), entre outros.

Nesse sentido, este trabalho torna-se relevante, pois é primordial que sejam feitas discussões sobre temas tão próximo a nossa realidade vigente, tais como controle, manipulação, poder, distopia, barbárie, desigualdades, entre tantas outras questões que nos cercam, massacram e oprimem, visto que precisamos nos conscientizar cada vez mais sobre o nosso papel enquanto cidadão na atualidade e nos posicionarmos frente ao recente quadro político que se instaurou em nosso país, sob o imediato risco de perdermos as nossas conquistas democráticas. Portanto, esse trabalho nos incita, porque traz à baila reflexões a respeito da condição humana nesse mundo contemporâneo, permeado de incertezas, complexidades e, quiçá, caos.

Isso posto, vale relembrarmos o enredo do livro 1984 que se desenrola a partir do relato de Winston Smith, personagem que trabalhava no Ministério da Verdade, exercendo a função de alterar todos os dados que não fossem correspondentes ao discurso do Grande Irmão, em razão de "quem controla o passado controla o futuro; quem controla o presente controla o passado" (ORWELL, 2009, p. 47).

Logo, é fácil percebermos um regime extremamente manipulador, totalitário, que desenrola sob o rígido controle do Grande Irmão, através da adulteração de informação e, pior, por meio de uma espécie de câmera, teletela, instaladas em cada residência e em cada local de trabalho, a partir da qual o governo fiscalizava todas as ações e palavras ditas. Nesse sentido, já de início, podemos entrelaçar a ficção e a realidade, a partir da relação entre o reality show intitulado Big Brother Brasil, apresentado pela Rede Globo de Televisão, que nos remete a uma sutil alusão sobre o procedimento de vigilância retratada no livro e o slogan da campanha do Grande Irmão, em 1984.

É notório a relação quase intrínseca entre o reality show e o mecanismo de vigilância do Grande Irmão, visto que ambos possuem o intuito de vigiar e monitorar o comportamento 
dos indivíduos através de câmeras. Se a imagem do Grande Irmão, no livro 1984, pode nos horrorizar, nos fazendo até mesmo acreditar que essa situação é totalmente bizarra, por outro lado, o reality show, Big Brother Brasil, é um programa de alto índice de audiência em sua $20^{\mathrm{a}}$ edição.

O referido programa consiste no isolamento dos participantes em uma casa construída para esse fim, sendo vigiados por câmeras durante todo esse período de reclusão. Esses participantes não têm contato com o mundo exterior, apenas com o apresentador do programa que certamente é uma referência ao Grande Irmão de 1984, pois a sua imagem ou aparição é sempre enaltecida e reverenciada pelos participantes da casa.

Segundo o professor Bucci (2002), esse tipo de programa é uma versão circense de delito, porque transmite valores torpes, como "a fama vale qualquer humilhação", "a exploração da sensualidade". "a erotização precoce", entre outros. No entanto, apesar de várias críticas, o programa resiste há duas décadas e continua a hipnotizar vários telespectadores fascinados em poder vigiar a privacidade dos participantes e exercer, de certa forma, o papel do Grande Irmão.

Além disso, cabe evidenciar um outro artificio apresentado em 1984, que é o controle do pensamento livre. Se, por acaso, alguém discordasse ou afirmasse algo que fosse contrário ao interesse do governo estaria condenado a pena de morte pelo crime de ideia, ou crimideia, uma vez que, "o pensamento-crime não acarreta a morte: o pensamento-crime é a morte" (ORWELL, 2009, p. 40).

Diante dessas e tantas outras barbáries relatadas pelo personagem principal, Winston Smith, verificamos que essa obra trata de um gênero literário distópico, que surgiu no início do século XX, ao demonstrar o pessimismo, o desencanto, o desalento dos escritores com o progresso, a ciências e a tecnologia. Por esse viés, Hilário (2013) ratifica que esse tipo de gênero geralmente surge com o principal objetivo de avaliar as atrocidades ocorridas em algum momento da história no âmbito social, levando ao extremo elementos culturais já presentes no nosso cotidiano. De fato, nesse período, algumas obras foram publicadas com o intuito de descrever sociedades imaginárias, onde eram instaurados regimes totalitários, que predominavam um implacável controle do governo, cerceando a liberdade da sua população, como também, uma intensa manipulação da informação, camuflando e distorcendo a verdade.

Partindo desses pressupostos e com base no contexto atual, em que as mídias e redes sociais ocupam cada vez mais os espaços dessa aldeia global, é observável que os sujeitos se 
encontram em constante instabilidade pelo caráter fluido da sociedade pós-moderna, como bem salientam Bauman (2001) e Hall (2014), ao explanarem sobre as relações efêmeras e a descentralidade do sujeito. Como visto, a disseminação de discursos manipuladores, de notícias inverídicas e, ainda, a proliferação de boatos, podem favorecer o aparecimento de regimes totalitários, antidemocráticos, tirânicos e ditadores, como foi a disputa presidencial de Donald Trump, nos Estados Unidos, em 2016, ou, ainda, a Primavera Árabe, em 2010. Em contrapartida, diversas formas de linguagens e artes, principalmente literárias, podem auxiliar no processo de transformação da realidade revertendo o engodo, a mentira e a distorção da realidade muitas vezes impostas pelas mídias, sob o comando de uma classe populista. Aliado a esse pensamento, Facini (2004, p. 25) esclarece que:

A literatura não é espelho do mundo social, mas parte constitutiva desse
mundo. Ela expressa visões de mundo que são coletivas de determinados
grupos sociais. Essas visões de mundo são informadas pela experiência
histórica concreta desses grupos sociais que as formulam, mas são também
elas mesmas construtoras dessa experiência. Elas compõem a prática social
material desses indivíduos e dos grupos sociais aos quais eles pertencem ou
como os quais se relaciona.

A título de ilustração, ainda vale citar alguns exemplos literários e midiáticos, como o livro The handmaid's Tale (1985), adaptada para TV, em 2017. Também a obra Fahrenheit 451 (1953), Admirável Mundo Novo (1932) e, por fim, o livro de origem russa traduzida para o português, Nós (1924). Além dessas obras citadas, temos as produções audiovisuais que ganham corpo cada vez mais nas plataformas digitais e televisivas, como Black Mirror (2011), The Man in the High Castle (2015), entre outras. Todas essas produções possuem em comum o gênero distópico, que visam um único e primordial objetivo, demonstrar a recorrência do autoritarismo, da manipulação, do abuso, nas diversas esferas, por diferentes linguagens. Dessa maneira, essas obras literárias e midiáticas, podem promover, mesmo que paulatinamente, o senso crítico dos seus leitores frente aos padrões e condutas nocivas dos modelos impostos pelos regimes fascistas.

\section{1984: Como A Ficção se Confronta com a Realidade}

As posições dos regimes políticos enquadrados em regimes da direita protagonizam no poder ao longo do tempo, possuindo discursos e posições muitas vezes autoritárias. Orwell (2009), em sua obra clássica 1984, apresenta algumas questões que nos auxiliam a pensar os 
dispositivos de controle e manipulação social. Compreendemos, de acordo com Foucault (2009), que dispositivo é:

um conjunto decididamente heterogêneo que engloba discursos, instituições, organizações arquitetônicas, decisões regulamentares, leis, medidas administrativas, enunciados científicos, proposições filosóficas, morais, filantrópicas. Em suma, o dito e o não dito são os elementos do dispositivo. O dispositivo é a rede que se pode tecer entre estes elementos (FOUCAULT, 2000, p. 04).

Reconhecidamente, a vigilância da tecnologia torna-se cada dia mais presente, podendo até mesmo se enquadrar no conceito de dispositivo dado por Foucault (2000), pois promove a circulação de discursos exercidos por sujeitos, em determinado momento histórico sob possíveis condições de possibilidades, o que nos leva a perceber a similaridade entre a obra distópica de 1984 e atualidade brasileira.

Contribuindo com a conjuntura política e midiática, Charaudeau (2007, p. 257) sinaliza que uma parte interessada na construção de processos de controle social pelo dispositivo midiático é advinda das instâncias políticas que, de modo geral, e até abstrato, se tornam formas de vigilâncias inseridas no nosso cotidiano. Daí, se estabelecem, portanto, os monitoramentos de controle e, por consequência, a perda gradual da liberdade individual. Dito isso, os regimes extremistas se revestem de medidas rigorosas e disciplinares para policiar e disseminar ideologias sobre a sociedade, fazendo com que através dos meios de comunicação se aniquilem, por exemplo, os movimentos de resistência. Assim, para Foucault (1987)

O poder disciplinar é com efeito um poder que, em vez de apropriar e de retirar, tem como função maior "adestrar"; ou sem dúvida adestrar para retirar e se apropriar ainda mais e melhor. Ele não amarra as forças para reduzi-las; procura ligá-las para multiplicá-las e utilizá-las num todo [...]. "Adestra as multidões confusas [...] (FOUCAULT, 1987, p. 195).

Na obra em análise, 1984, essa forma de manipulação é exercida, principalmente, pelo Ministério da Verdade, uma divisão do partido responsável por editar e distorcer completamente os fatos reais, tantos os decorrentes do passado quanto os que acontecem no presente. Essa missão é específica e realizada pelo protagonista já citado, Winston Smith, que trabalha no Ministério e colabora na alteração dos fatos, induzindo a população a acreditar naquilo que era imposto pelo Grande Irmão como verdade absoluta. 
Outro ponto que merece destaque em 1984 é o momento no qual o partido diariamente reúne todos os cidadãos em frente a uma teletela e, em seguida, transmite um pequeno vídeo, com o traidor do partido, considerado o inimigo do povo, Emmanuel Goldstein. Essa ocasião é tida como dois minutos de ódio. Nesse momento, a população expressa sua fúria e rancor, por meio de ameaças e insultos contra a imagem de Goldstein na teletela. Nessa perspectiva, fazendo um paralelo com a nossa atualidade, os dois minutos de ódio podem ser comparados aos cidadãos, no momento da propaganda eleitoral gratuita, ocorrida nos horários nobres da rádio e da televisão, devido aos inúmeros casos de corrupção que são frequentemente notificados.

Nos termos apontados, sem sombra de dúvidas, “[...] as distopias buscam o assombro, ao acentuar tendências contemporâneas que ameaçam a liberdade" (JACOBY, 2007, p. 40). Assim sendo, como não poderia ser diferente, o romance em estudo retrata de maneira excepcional uma sociedade controlada pelo estado, que distorce a realidade e oprime a população local, além de torturar os que são contra o regime vigente. Como visto,

[...] a relação de domínio não está fundada apenas na supremacia da força. Passado o tempo da conquista, soa a hora do controle dos espíritos. E é tanto mais fácil dominar, quando o domínio permanece inconsciente. Daí a importância da persuasão clandestina e da propaganda secreta, pois, a longo prazo, para todo império que deseja durar, a grande aposta consiste em domesticar as almas, torná-las dóceis e depois subjugá-las (RAMONET, 2002, p.21).

À luz dessas reflexões, vale retomar um outro termo que se encontra na direção oposta da distopia: a utopia, que foi citado pela primeira vez por Thomas More, no século XVI, em 1516. Dentre algumas de suas definições está a representação de uma sociedade também imaginária, na qual existe um ambiente harmonioso, em que todos os cidadãos podem usufruir de sua total liberdade. Muitos acreditavam que nesse lugar, tudo deveria acontecer para um bem comum dos indivíduos. Nessa linha de raciocínio, ancorados por Brasil (2009, p. 6), a utopia pode ser considerada como "a negação da sociedade presente, é ultrapassar os limites impostos por esta sociedade, é descontinuidade histórica, é resistência”. Por sua vez, Sousa Santos (2005) alerta que a utopia é necessária nesse novo tempo, em que alastram as desigualdades sociais, o neoliberalismo, a globalização perversa e o fascismo social.

Com efeito, é visível o posicionamento crítico de Orwell sobre a realidade de sua época, pois o livro foi escrito em um imediato pós Segunda Guerra Mundial, com a qual ele 
manteve constante contato. Logo, verificamos uma forma de aviso para uma realidade futura, como foi 1984 ou poderia ser 2020. Uma realidade marcada pela repressão e pelo totalitarismo, que abordaremos, agora, em linhas gerais, sob a perspectiva de Arendt (2012).

O totalitarismo surgiu no século XX, porém com raízes no século XVIII. Foi ocasionado pelo fim da Primeira Guerra Mundial, em que os países envolvidos saíram arcando com algumas consequências negativas. Com o crescimento do desemprego em massa e, consequentemente, a crescente miséria, e, ainda, a Crise de 1929, resultaram nas instabilidades sociais da época. Vale destacar, que esse contexto social foi propicio para o desenvolvimento de regimes totalitários, como o Nazismo e o Fascismo.

Para um melhor entendimento do que seja esse sistema, Arendt (2012) faz o seguinte esclarecimento:

O totalitarismo não procura o domínio despótico dos homens, mas sim um sistema em que os homens sejam supérfluos. O poder total só pode ser conseguido e conservado num mundo de reflexos condicionados, de marionetes sem o mais leve traço de espontaneidade (ARENDT, 2012, p. $605)$.

Nesse pormenor, percebemos como a maioria das instituições midiáticas, aliadas ao governo, podem exercer um papel despótico, já que invariavelmente distorcem ou omitem informações para camuflar a realidade dos fatos, nos transformando em meros marionetes. Portanto, nesse contexto, cabe refletir se estamos vivendo em uma sociedade democrática ou em um sistema totalitário. Sendo que, no mundo contemporâneo em que as relações não se configuram enquanto estáveis, mas, sim, fluídas e descentradas, precisamos nos ater as formas de camuflagem dos regimes de dominação, pois como afirma Bauman e Donskis (2014):

O mal não está confinado às guerras ou às ideologias totalitárias. Hoje ele se revela com mais frequência quando deixamos de reagir ao sofrimento de outra pessoa, quando nos recusamos a compreender os outros, quando somos insensíveis e evitamos o olhar ético silencioso (BAUMAN; DONSKIS, 2014, p. 15).

E, por fim, será que a tão sonhada utopia poderá realmente nos levar a mudança e a transformação da nossa sociedade em pleno século XXI, uma vez que esse século, aparentemente, colocou um fim em um grande período utópico, na medida em que "propôs-se e defendeu-se a inutilidade de pensar o futuro, quer numa visão positiva ou negativa" 
(BRASIL, 2009, p. 11). Ou, então, como poderemos ser resistência, aos moldes de Foucault (2009), quando ele tão bem evidencia

[...] que lá onde há poder há resistência e, no entanto (ou melhor, por isso mesmo) esta nunca se encontra em posição de exterioridade em relação ao poder. [...] Mas sim resistências, no plural, que são casos únicos: possíveis, necessárias, improváveis, espontâneas, selvagens, solitárias, planejadas, arrastadas, violentas, irreconciliáveis, prontas ao compromisso, interessadas ou fadadas ao sacrifício [...] (FOUCAULT, 2009, p. 91).

Tais inquietações são imperativas, pois precisamos construir um mundo melhor, sem opressão, sem manipulação, sem violação aos direitos humanos, a fim de que possamos viver com a liberdade de traçar os nossos próprios destinos. Essa é a nossa grande utopia!

\section{Metodologia}

Esta pesquisa é bibliográfica, pois de acordo com Gil (2002), ela é aplicada em materiais já elaborados, a exemplo de livros, publicações periódicas e impressos diversos. Assim, este trabalho tem como objeto de estudo o livro 1984, de George Orwell, em que estão sendo investigados o contexto histórico em que o livro foi escrito, os elementos característicos do gênero literário distópico e, ainda, estão sendo cotejados a obra ficcional com o cenário brasileiro.

Para tanto, também estão sendo utilizados artigos de revistas e jornais (Veja, Isto É, Folha de São Paulo, entre outros) buscando comparar as duas realidades e também analisar como as informações transmitidas pela mídia conseguem influenciar, manipular e controlar a nossa sociedade. Portanto, este trabalho busca a compreensão do gênero literário distópico e seus desdobramentos, num processo comparativo, interpretativo e reflexivo, enfocando as relações entre o livro 1984 e o cenário sócio-político do Brasil.

\section{Resultados e Discussão}

Esta pesquisa, em sua fase inicial, tem como principal objetivo analisar o cenário de horror implantado pelo regime totalitário, do livro 1984. Em face dessa perspectiva, buscamos refletir sobre a imposição desse poder e relacioná-lo ao tempo em que vivemos. Com isso em mente, só para ilustrar, na última parte do livro, em que Winston Smith passa por todo um processo de recondicionamento, por meio de tortura, passamos a compreender, de fato, os aspectos totalitários, conforme argumenta Arendt (2012). 
A partir desse momento, tomamos ciência dos pilares que sustentam o governo do Grande Irmão, que muito bem poderia ser comparado com o nosso regime dito democrático brasileiro: o controle das informações através das teletelas, que serviam tanto para vigiar a população como para fazer propaganda do sistema governamental; o duplipensamento, aceitação de duas crenças contraditórias como corretas; e, a Novafala, simplificação da língua, favorecendo a redução do vocabulário, e, por consequência, a impossibilidade de formação de ideias e reflexões.

Certamente, a função desses três pontos era destruir a força do pensamento e a manipulação da sociedade para que a classe dominante mantivesse o poder. Relacionando tais fatos à nossa realidade, podemos perceber nitidamente o controle de informações, através das câmeras de segurança nas ruas, dos smartphones, dos aplicativos, entre outros, que direta ou indiretamente, nos manipulam, como ficou evidente nas últimas eleições presidenciais no Brasil por um crescente número das chamadas Fake news. Para compreender esse fenômeno que explodiu nas redes e mídias sociais no período eleitoral, trazemos a contextualização e o conceito do Observatório da Comunicação (Obercom) de 2018:

Com a Internet, foram criadas as condições tecnológicas para o surgimento de uma sociedade em rede e, por sua vez, de uma prática de comunicação em rede, a qual proporcionou um espaço de expressão livre onde praticamente qualquer informação pode ser produzida, transmitida e recebida [...] O problema das fake news, da forma como hoje o entendemos, encontrasse ligado à sociedade em rede, à comunicação em rede e às próprias redes sociais, uma vez que se criam os pressupostos para reforçar ideias e opiniões numa perspectiva não dialógica" (CARDOSO, G.; et al. 2018, p.6).

Dessa forma, nos preocupamos se existe um terreno fértil para propagação de ideias totalitárias aqui no Brasil, uma vez que já se pode verificar que a história e os fatos estão sendo constantemente alterados, modificados e reeditados tal qual no clássico 1984.

\section{Conclusões}

Não podemos afirmar que Orwell, em seu livro 1984, estava fazendo uma profecia, que poderia ter sido o ano de 1984 ou a outros anos futuros. Mas, seguramente, podemos afirmar que essa obra prima nos leva a reflexões relevantes para o contexto histórico atual.

Nesse sentido, só para exemplificar, urge uma pausa para analisarmos os três slogans do partido: "guerra é paz; liberdade é escravidão; ignorância é força". Uma ambiguidade do 
duplipensamento, que nos leva a comprovar como a realidade pode ser facilmente manipulada, pois, "toda manipulação se acompanha então de uma enganação cuja vítima é manipulada" (CHARAUDEAU, 2007, p. 252). Através dessa grande ironia conseguimos perceber os conceitos intrínsecos de cada termo sendo distorcidos. Em outras palavras, a mentira pode parecer verdade, como afirma Winston Smith, "A mentira torna-se verdade e depois mentira outra vez" (ORWELL, 2009, p. 47).

Para finalizar, o livro 1984 nos impulsiona a uma visão mais crítica com os meios de comunicação, evitando, assim, que sejamos meros papagaios ambulantes, uma vez que as ideologias propagadas podem moldar o homem e a realidade em que ele está inserido. Portanto, será que o futuro distópico pode estar entre nós?

\section{Referências}

ARENDT, H. Origens do totalitarismo. São Paulo: Companhia das Letras, 2012.

BAUMAN, Z. Modernidade líquida. Tradução de Plínio Dentzien. Rio de Janeiro: Jorge Zahar, 2001.

BAUMAN, Z.; DONSKIS, L. Cegueira moral: a perda da sensibilidade na modernidade líquida. Tradução de Carlos Alberto Medeiros. Rio de Janeiro: Editora Zahar, 2014 BRASIL, M. S. Utopia e o século XXI: novas controvérsias. In: XIV Congresso Brasileiro de Sociologia, CT-UFRJ. Consensos e controvérsias da Sociologia. Rio de Janeiro, julho, 2009.

BUCCI, E. Quanto vale a sua privacidade? Revista Nova Escola, São Paulo, abr. 2002. Seção De olho na televisão.

CARDOSO, G.; et al. As fake news e a sociedade pós-verdade: uma contextualização conceptual. As fake News numa sociedade pós-verdade: contextualização, potenciais soluções e análise. Observatório da Comunicação (Obercom): Lisboa, Portugal, jun. 2018. Disponível em: https://obercom.pt/wp-content/uploads/2018/06/2018-Relatorios-ObercomFake-News.pdf. Acesso em: 10 fev. 2020.

CHARAUDEAU, P. Discurso das mídias. São Paulo: Contexto, 2007.

FACINI, A. Literatura e sociedade. Rio de Janeiro: Jorge Zahar Editores, 2004.

FOUCAULT, M. Vigiar e punir: nascimento da prisão. Tradução de Raquel Ramalhete. 27. ed. Rio de Janeiro: Vozes, 1987.

FOUCAULT, M. Os intelectuais e o poder - conversa entre Michel Foucault e Gilles Deleuze. In: . Microfísica do poder. Rio de Janeiro: Graal, 2000, p. 01-47 
FOUCAULT, M. O dispositivo de sexualidade. In: A história da sexualidade I: a vontade de saber. Rio de Janeiro: Graal, 2009. p. 73-125.

GIL, A. C. Como elaborar projetos de pesquisa. 3. ed. São Paulo: Editora Atlas, 2002.

HALL, S. A Identidade cultural na pós-modernidade. Tradução de Tomaz Tadeu da Silva e Guacira Lopes Louro. São Paulo: Lamparina Editora, 2014.

HILÁRIO, L. C. Teoria crítica e literatura: a distopia como ferramenta de análise radical da modernidade. Anuário de Literatura da Universidade Federal de Santa Catarina, Florianópolis, v.18, n. 2, p. 201-215, 2013.

JACOBY, R. Imagem imperfeita: pensamento utópico para uma época antiutópica. Tradução de Carolina de Melo Bomfim Araújo. Rio de Janeiro: Civilização Brasileira, 2007.

MORUS, T. A Utopia ou o tratado da melhor forma de governo. Tradução de Paulo Neves. Porto Alegre: LP\&M, 1997.

ORWELL, G. 1984. Tradução de Alexandre Hubner e Heloísa Jahn. São Paulo: Companhia das Letras, 2009.

RAMONET, I. Propagandas silenciosas: massas, televisão, cinema. Rio de Janeiro: Vozes, 2002.

SOUSA SANTOS, Boaventura. Fórum Social Mundial: manual de uso. São Paulo: Cortez, 2005.

\section{Notas}

i Etimologicamente, distopia é palavra formada pelo prefixo dis (doente, anormal, dificuldade ou mal funcionamento) mais topos (lugar). Num sentido literal, significa forma distorcida de um lugar. Tem como principal objetivo avaliar as atrocidades ocorridas em algum momento da história no âmbito social (HILÁRIO, L. C, 2013).

\section{Sobre as autoras}

Sigrid Rochele Gusmão Paranhos Magalhães é Professora Assistente da Universidade do Estado da Bahia - UNEB, DCH VI/Caetité, atuando nas áreas de Literaturas de Língua Inglesa e Linguística Aplicada. Mestre e doutoranda em Língua e Cultura pela Universidade Federal da Bahia - UFBA. Tem Especialização em Literatura Brasileira e graduação em Letras com Habilitação em Língua Inglesa e Literaturas pela Universidade Estadual do Sudoeste da Bahia - UESB. Membro da Cátedra UNESCO Políticas Linguísticas para o Multilinguismo. Endereço eletrônico: sigrid.rochele@gmail.com 
Larissa Lopes Meira é estudante de graduação do Curso de Licenciatura em Letras, Língua Inglesa e Literaturas, pela Universidade do Estado da Bahia UNEB, Departamento de Ciências Humanas Campus VI/Caetité.

Endereço eletrônico: larissameira.1111@gmail.com

Valdineide Jesus de Oliveira é estudante de graduação do Curso de Licenciatura em Letras, Língua Inglesa e Literaturas, pela Universidade do Estado da Bahia - UNEB, Departamento de Ciências Humanas - Campus VI/Caetité. Membro do Grupo de Pesquisa AUDiscurso - Laboratório de Estudos Audiovisual e do Discurso, da Universidade do Estado da Bahia - UNEB.

Endereço eletrônico: valdineide.oliveira@ outlook.com 